\title{
New evidence on teachers' working hours in England. An empirical analysis of four datasets
}

\author{
Rebecca Allen \\ Asma Benhenda \\ John Jerrim \\ Sam Sims \\ UCL Institute of Education
}

December 2019

\begin{abstract}
Surveys have revealed that teachers in England work far longer hours than their international counterparts, causing serious concern amongst both policymakers and the profession. Indeed, consecutive Secretaries of State for Education have now implemented policies aimed at reducing the number of hours teachers spend at work. Despite this, surprisingly little is known about the structure of and changes to teachers' working hours. We address this gap in the evidence base by analysing four different datasets, providing the most comprehensive assessment of teachers' working hours to date. Working hours remain high: a quarter of teachers work more than 60 hours per week during term time, $40 \%$ report that they usually work in the evening and around 10\% during the weekend. However, contrary to current narratives, we do not find evidence that average working hours have increased. Indeed, we find no notable change in total hours worked over the last twenty years, no notable change in the incidence of work during evenings and weekends over a fifteen-year period and no notable change in time spent on specific tasks over the last five years. The results suggest that policy initiatives have so far failed to reduce teachers' working hours and that more radical action may need to be taken in order to fix this problem. The article concludes with a discussion of how official data on working hours could be improved.
\end{abstract}

Key Words: Teachers, workload, working hours, measurement error

Contact details: John Jerrim (J.Jerrim@ucl.ac.uk) Department of Social Science, UCL Institute of Education, University College London, 20 Bedford Way London, WC1H 0AL

Acknowledgements: The Nuffield Foundation is an independent charitable trust with a mission to advance social well-being. It funds research that informs social policy, primarily in Education, Welfare, and Justice. It also funds student programmes that provide opportunities for young people to develop skills in quantitative and qualitative methods. The Nuffield Foundation is the founder and co-funder of the Nuffield Council on Bioethics and the Ada Lovelace Institute. The Foundation has funded this project, but the views expressed are those of the authors and not necessarily the Foundation. Visit www.nuffieldfoundation.org. We are grateful for their support. Helpful comments have been 
received on the draft from our project steering group, who we would like to thank for their input and support. 


\section{Introduction}

Individuals can allocate their time to either work or leisure. Spending too long at work is negatively associated with job satisfaction (Gazioglu \& Tanzel, 2006; Hans, Trinkoff \& Gurses, 2015), well-being (Wunder and Heineck 2012, Angrave \& Charlwood, 2015) and mental and physical health (Artazcoz et al., 2009; Afonso et al., 2017). Long hours can also have a negative effect on worker productivity (Collewet \& Sauermannn, 2017; Dolton, Howorth, \& Abouaziza, 2016) which, at the extreme, means that hours could be reduced without any reduction in output (Penceval, 2014). The structure of working hours, or shift pattern, also has an influence on individuals above and beyond the total number of hours worked (Bambra et al., 2008), with evenings and weekends providing important opportunities to recover from work (Demerouti et al., 2009; Fritz \& Sonnentag, 2005).

The working patterns of teachers are unusual in a number of ways. They tend to work in intensive six to eight week bursts during term time, punctuated by one to two weeks of paid leave and then a further six weeks of paid leave during the summer (Eurydice, 2018). As a result, full-time teachers are contracted to work fewer days than full-time employees in most other professions. In Europe, for example, full-time teachers tend to work between 170 and 190 days per year, compared to around 220 for other employees (Eurydice, 2018; Messenger, Lee, \& McCann, 2007). During term-time, teaching feels very intense (Green, Felstead, Gallie, \& Hensecke, 2018) and education researchers have long emphasised the emotional and relational demands of working with pupils (Sutton \& Wheatley, 2003). Perhaps as a result, teachers display higher level of stress and burnout than other occupations (Johnson et al., 2005; Innstrand et al., 2011).

In England, the context for this research, teachers work unusually long hours (Kodz et al. 2003). For example, the Teaching and Learning International Survey 2018 (TALIS) showed primary and lower secondary school teachers in England to be working longer hours than teachers in almost every other country covered by the data (Jerrim and Sims 2019). The government's own surveys (Deakin et al., 2010; TNS-BRMB, 2014; Higton et al., 2017) also suggest that the workload of teachers in England rose between 2010 and 2016.

Teacher workload has since become a topic of intense policy interest because research with inservice and former teachers has concluded that workload - in particular the overly-bureaucratic requirements for planning, marking and data entry - are driving teachers out of the profession (Gibson, Oliver \& Dension, 2015; DfE, 2018a). England already faces a severe shortage of 
teachers (Sims, 2018a) and the Department for Education in England - under the political leadership of Nicky Morgan, then Justine Greening, and latterly Damian Hinds - has responded by introducing several policy initiatives to address workload. This includes moving to a simpler system of accountability (DfE, 2017), producing a teacher workload "toolkit" (DfE, 2019a) and setting-up a number of workload review groups (DfE, 2018b). ${ }^{1}$

As part of this commitment to reducing workload, the Department for Education in England has "committed to collecting robust evidence on teacher workload at least every 2 years" (Department for Education 2019). Thus far, this has consisted of the 2016 Teacher Workload Survey (Higton et al., 2017) and the 2018 Teaching and Learning International Survey (TALIS). Unfortunately, this data has a number of limitations. First, response rates tend to be very low. For instance, the total final response rate to the 2016 workload survey was less than 10 percent $^{2}$. It is therefore essentially a convenience sample and hence unlikely to be representative of the wider teacher population. Second, all information is self-reported and relies upon teachers recalling and accurately reporting information on weekly hours spent upon different tasks (e.g. questions such as "how many hours did you spend marking during your most recent full working week?"). Third, no attempt has been made to capture how many hours teachers work during school holidays, with questions typically focusing upon usual working hours during school term-time. Fourth, most questions focus only upon teachers working hours in their main job. Yet there is evidence that more than one-in-ten teachers earn money elsewhere, as private tutors, examiners or creating teaching resources (Allen and McInerney, 2019). Fifth, and crucially, there is currently limited evidence as to how teachers' working hours have changed over time, since the low response rates and changing methodology in government surveys limit the extent to which valid comparison can be drawn (Deakin et al., 2010; TNS-BRMB, 2014; Higton et al., 2017).

This paper aims to plug this gap in the existing evidence by drawing on a range of different data sources: three nationally representative data sources (TALIS, the Labour Force Survey and UK Time-Use diaries) as well as more illustrative information gathered from a longitudinal convenience sample (Teacher Tapp). As we shall discuss, this evidence is far from perfect and part of our contribution to the debate is highlighting the limitations of the data available and

\footnotetext{
${ }^{1}$ Further details on the Department for Education's on-going policy interventions in this area can be found at https://www.gov.uk/government/publications/reducing-teachers-workload/reducing-teachers-workload

${ }^{2}$ The technical report to the 2016 workload survey notes that the school response rate was 24 percent (Higton et al 2017:42). The teacher response rate within participating schools was then 34 percent (Higton et al 2017:43). Multiplying these two figures together gives an overall response rate of 8 percent.
} 
suggest ways in which it could be improved. Nevertheless, our intention is to provide the best possible overview using existing sources.

Our key findings are as follows. Average teacher working hours in England is high, both in absolute terms and relative to other countries. The median teacher works a fifty hour week, putting in just under ten hours on a typical term-time weekday. A quarter of teachers work more than 59 hours a week, putting in 10.7 hours on the average weekday. Around four in ten teachers report that they 'usually' work in the evening, 10\% at the weekend and $7 \%$ at night. Teachers in England work 8 hours per week longer than the OECD average. Despite this, and contrary to the prevailing view, we do not find evidence that working hours have increased in recent years. Indeed, total working hours have remained relatively stable between 46 and 48 hours per week over the last twenty years and the proportion of teachers who report working evenings and weekends has also been broadly stable since 2005 .

The paper now proceeds as follows. Section 2 provides an overview of our key data sources. This is followed in section 3 with a critical discussion of how well teachers' working hours are likely to be measured within existing datasets. Results are presented in section 4, with conclusions and directions for future research presented in section 5.

\section{Data}

\section{The Teacher and Learning International Survey (TALIS)}

TALIS is an international survey of teachers conducted by the Organisation for Economic CoOperation and Development (OECD). England participated in 2013 (lower secondary - key stage 3 teachers only) and in 2018 (primary and lower secondary teachers). The data are designed to be nationally representative, with schools first randomly selected (with probability proportional to size) and then twenty teachers randomly selected from within each sampled school. Both independent and state school teachers are included. The OECD set strict criteria for countries to be included in the study, which tends to yield high response rates. In 2013, the response rate in England was 75 percent at the school level and 83 percent at the teacher level. The analogous figures in 2018 were $82-85$ percent (primary and secondary, respectively) and 84-85 percent. In both years, the survey was conducted in England between March and May.

The TALIS survey includes three separate questions asking teachers about their working hours. First, teachers are asked to provide a figure for their total working hours in their most recent complete working calendar week: 
- Question 1: "During your most recent complete calendar week, approximately how many 60-minute hours did you spend in total on teaching, planning lessons, marking, collaborating with other teachers, participating in staff meetings and on other tasks related to your job at this school?" [A 'complete' calendar week is one that was not shortened by breaks, public holidays, sick leave, etc. Also include tasks that took place during weekends, evenings and other out of class hours].

The next two questions then ask about number of hours spent per week upon specific tasks. The first focuses specifically upon the amount of time spent upon teaching:

- Question 2a: Of this total, how many 60-minute hours did you spend on teaching during your most recent complete calendar week? [Please only count actual face to face teaching time].

With the subsequent question asking for separate figures for a series of auxiliary tasks, such as planning, preparation, administration and marking.

- Question 2b: As a teacher at this school, during your most recent complete calendar week, how many 60-minute hours did you spend on the following tasks? [Also include tasks that took place during weekends, evenings and other out of class hours. Please exclude all time spent teaching as this was recorded in the previous question].

- Individual planning or preparation of lessons either at school or out of school

- Team work and dialogue with colleagues within this school

- Marking/correcting students' work

- Student counselling (including student supervision, virtual counselling, career guidance and delinquency guidance)

- Participation in school management

- General administrative work (including communication, paperwork and other clerical duties you undertake in your job as a teacher)

- Communication and co-operation with parents or guardians

- Engaging in extracurricular activities (e.g. sports and cultural activities after school)

- Other tasks

Consequently, TALIS provides two figures for total working hours - based upon either a single question ( 1 above) or by adding together the time teachers report spending upon each of the different tasks ( $2 \mathrm{a}$ and $2 \mathrm{~b}$ above). 
TALIS has several advantages for our investigation. Importantly, the data are nationally representative with a high response rate. It also allows us to explore the time teachers in England say that they spend upon different tasks. Yet is also has limitations. First, one can only consider trends between 2013 and 2018, and then only for lower secondary teachers (data collection for primary teachers only began in 2018). Second, data is only collected for working during the school-term and not working during the school holidays. Indeed, data is only collected between March and May - which could be problematic if working hours vary across the academic year. Third, the data gathered require teachers to recall information about the number of hours they spend upon certain tasks per week; recalling such information and reporting it accurately may not be easy. Finally, it does not provide any evidence with respect to teachers' working patterns, such as the number of hours that they work in the evening (compared to during the day) and how many hours they work at weekends.

\section{The UK Labour Force Survey (LFS)}

The UK LFS is a household survey. A random sample of around 38,000 households has been contacted every quarter since 1992. There is a panel element to the LFS, with households remaining in the survey for five quarters when they are then replaced. Response rates at the household level remain reasonable, though they have declined over time. For instance, around 70 percent of sampled households participated in the LFS in the early 2000s compared to around 60 percent in more recent waves (http://www.hse.gov.uk/statistics/lfs/about.htm).

The LFS is a general population survey; unlike TALIS it is not specific to teachers. However, respondents are asked a series of questions about their job, with the dataset providing four-digit occupation (SOC) and industry (SIC) codes. It is hence possible to identify primary and secondary teachers and whether they work in the public or private sector. For instance, the 2010 SOC codes used in the most recent waves of the LFS allow us to identify the following groups of interest:

- $2314=$ Secondary education teaching professionals

- $2315=$ Primary and nursery education teaching professionals

- $2316=$ Special needs education teaching professionals

- $2317=$ Senior professionals of educational establishments

Moreover, the substantial number of households surveyed as part of the LFS means that there is a reasonable sample size for each of these groups in every quarter. For instance, in the July- 
September 2018 wave of the LFS ${ }^{3}$, there were 510 secondary teachers, 576 primary teachers, 123 SEN teachers and 143 "senior professionals of educational establishments" (e.g. headteachers $)^{4}$. These sample sizes are sufficient to provide a detailed picture of trends in teachers' working hours over time and, when pooling across multiple survey quarters/years, how working hours vary over the year.

Respondents to the LFS are asked several questions about the number of hours they work each week. Information is gathered with respect to their "usual hours" (i.e. how many hours they work in a typical week) and specifically for what is known as the "reference week" (this is typically the week before the LFS survey is conducted). Our particular interest is in the latter. In particular, as the LFS is conducted on a quarterly basis throughout the year, teachers' responses to working hours in the reference week can provide us with an idea of how much time teachers spend working during the school holidays.

The derivation of working hours information in the LFS is fairly complex. To begin, respondents are asked:

- "Do you ever do any work which you would regard as paid or unpaid overtime?" (Yes/No)

Individuals who say they never work overtime are then asked:

- "How many hours per week do you usually work in your (main) job/business - please exclude meal breaks?"

Responses to the question above is then treated as the number of hours that individuals not doing any overtime (paid or unpaid) work in a typical week.

For those respondents who say that they do sometimes work overtime (around 62 percent of teachers in the LFS in 2018) the information collected on working hours is more extensive. They are first asked the following three questions about their "usual" hours of work per week:

- “Thinking of your (main) job/ business, how many hours per week do you usually work? [please exclude meal breaks and overtime?]

\footnotetext{
${ }^{3}$ The total LFS sample size for the July-September 2018 quarter was 86,377, meaning that $1.6 \%$ of the total sample for this quarter were teachers (i.e. were assigned a SOC code of 2314, 2315, 2316 or 2317).

${ }^{4}$ Note that "senior professionals of educational establishments" (e.g. headteachers) was included as a separate category for the first time in the SOC2010 classification. In the SOC2000 and SOC1990 coding, used in earlier waves of the LFS, headteachers were included within codes 2314 or 2315 (primary/secondary education teaching professionals). Any changes in working hours pre/post 2010 in our results should hence be interpreted with care.
} 
- "How many hours paid overtime do you usually work per week?"

- "How many hours unpaid overtime do you usually work per week?"

The interviewer then confirms the summed total of the responses to these questions with the interviewee, thus providing information on the number of hours they work in a typical working week.

Respondents are then asked questions about the actual number of hours they worked within the reference week. Again, a single question is used to gather information from individuals who say that they never work any overtime:

- "Thinking now about the seven days ending Sunday the $<$ date entered $>$, how many hours did you actually work in your (main) job/business?” [please exclude meal breaks]

In contrast, respondents who indicate that they sometimes work overtime are again asked three separate questions, with the summed total treated as their total working hours in their main job during the reference week:

- "Thinking now about the seven days ending Sunday the $<$ date entered $>$, how many hours did you actually work in your (main) job/business?" [please exclude meal breaks and overtime]

- "How many hours paid overtime did you actually work in the week ending Sunday the $<$ date entered $>$ ?"

- "How many hours unpaid overtime did you actually work in the week ending Sunday the $<$ date entered $>$ ?"

For individuals who report working greater or fewer hours in the reference week than usual, they are asked about the reason(s) why (e.g. bank holiday, maternity leave, sick). Importantly, this information (along with the reference week date) can lets us identify how many hours teachers report working during school holidays.

A number of auxiliary questions of potential interest are also included within the LFS. Within more recent LFS waves some information has been gathered on working in the evening and weekends, though this part of the data collection is limited to certain LFS quarters/waves. This includes the following items:

- Whether the respondent usually or ever works in the evening

- Whether the respondent usually or ever works on a Saturday/Sunday

- Whether the respondent worked on any bank holiday during the last year 
Hence the LFS can also provide us with some information on the extent that teachers tend to work unsociable hours.

A final point to note about the LFS is its use of "proxy respondents" and the imputation of some values by carrying forward figures from a previous wave. It is recognised that proxy responses for certain questions is problematic (Thomsen \& Villund, 2011) and this includes working hours. Hence, within our analysis, we only include teachers where a personal interview was achieved and exclude cases where proxy responses or an imputed value from a previous wave was used.

The LFS has a number of strengths. The survey is designed to be nationally representative and is one of the most respected sources of labour market information available in the UK. It has been running in its current format since 1992 and enables investigations of trends in teachers' working hours over a long period of time. The sample size for teachers is reasonably large and the survey is conducted throughout the year. It hence allows us to explore variation in working hours both during term-time and in school holidays. Different groups of teachers can be identified, meaning we can explore differences between primary, secondary, SEN and headteachers (at least in more recent waves). Finally, unlike most other resources, it provides important detail on matters such as working in second jobs and at evening/weekends.

Yet the LFS also suffers from certain limitations. As the data are collected using only broad questions (e.g. usual hours, overtime hours, etc) it does not enable us to investigate the time that teachers spend working on different tasks. Moreover, it is likely that recalling and selfreporting a figure for total working hours is likely to be subject to some measurement error (see section 3 below for further details). Response rates to the LFS are also moderate, with household response rates now standing at around 60 percent. Although this is much higher than the Department for Education's Teacher Workload Survey, it is far from perfect. Yet, despite these limitations, the LFS remains an important (and somewhat underutilised) resource that can contribute to our understanding of the hours that teachers work.

\section{United Kingdom Time Use Diaries}

The UK Time-Use Surveys were conducted in 2000/01 and 2014/15. Nationally representative household samples were drawn, although final response rates were somewhat disappointing. For instance, in the 2014/15 study, the household response rate was 40 percent, with a final diary completion rate of 33 percent. Nevertheless, from those individuals who did respond, very rich information about time-use was collected. This revolved around the time-diaries 
which individuals were required to complete for two different days within a given week (one weekday and one day at the weekend). These diaries divided the day into a series of 10-minute slots. Within each slot respondents were asked what their main activity was (e.g. eating breakfast) and if they were doing anything else at the same time (e.g. checking work emails). They were also asked about the location of the activity (e.g. at home, at work) and how much they enjoyed the activity on a seven-point scale. Upon completion of the diary, respondents were asked a series of questions such as whether it was an "ordinary" or "unusual" day, whether they were sick/on holiday and when the diary was completed (e.g. as the day progressed, at the end of the day, later in the week). Respondents also provided information about their current occupation, which have been converted into four-digit SOC 2000 codes. Our analysis includes any individual who was classified as being in paid employment and working full-time as either a primary, secondary, SEN or headteacher. This resource hence has the potential to provide new insights into the working hours of teachers and time-use during a standard day.

The key advantage of the UK Time Use Diaries (TUDs) is that the diary method is likely to limit recall error, relative to asking people to retrospectively estimate working hours for the preceding week. The key limitation with the UK TUDs for our purpose is the small sample size and likely biased sample due to non-response. For instance, after imposing our sample restrictions, there were only around 90 teachers with information available in 2000/2001, with a similar number in 2014/15. Consequently, all estimates using these data are surrounded by wide confidence intervals. This important limitation means that results using these data will be exploratory and subject to a non-trivial degree of uncertainty.

\section{$\underline{\text { Teacher Tapp }}$}

Teacher Tapp is a mobile phone-based survey app that collects daily information from a convenience sample of teachers in England (see teachertapp.co.uk for further details). At the time of writing (July 2019), there were around 3,500 daily respondents, with participants answering three questions each day.

As with time use diaries, the Teacher Tapp surveying approach allows us to compare daily reports of working patterns with weekly recollection of hours. In the week November $20^{\text {th }} 2018$ to November $26^{\text {th }} 2018$, panellists were asked the following question on working hours for seven consecutive days:

- How many hours in total did you work yesterday? (Please exclude commuting time and include all teaching, planning, marking and meeting time). 
Responses were given in two-hour bands (e.g. 7-9 hours). At the end of the week, on November $28^{\text {th }} 2018$, teachers were asked to recall their total hours in the previous working week (with responses in 10-hour bands):

- How many hours do you think you worked last week?

In total, 854 Teacher Tapp users responded to all these questions. This resource hence provides us with another way to investigate the consistency of teachers' reported working hours using different survey questions (i.e. daily versus weekly recall).

The strengths of the Teacher Tapp data, and how it complements our analysis of other sources, is the detail that has been collected about very specific aspects of teachers' jobs that most other large-scale survey data (which attempts to represent the wider population) is poorly equipped to do. For example, we can learn about:

- How long lunchtime is and what activities do teachers during it

- Whether teachers find it hard to find time to go to the toilet during the work day

- Whether teachers had the television on whilst they were marking students' work on a particular night

The main limitation of the Teacher Tapp data is that it is a convenience sample, meaning results should be treated as indicative rather than representative of the teacher population in England as a whole. All results from the survey are reweighted to match the teacher population along key observable characteristics (gender, age, seniority, phase and school type/location). However, we do not know how the unobservable characteristics of the Teacher Tapp respondents differ from the teaching population, particularly in our case in relation to working patterns.

\section{How well are working hours measured?}

To begin, we exploit the fact that teachers report their working hours in two different ways in TALIS 2013 (a single total weekly figure and a weekly figure for a set of different tasks) to consider the internal consistency of their responses. In other words, do teachers' report the same total working hours regardless of the question they are asked? The answer can be found in Figure 1. This plots, for England, total working hours when answered in a single question along the y-axis and total working hours based upon responses to multiple questions along the $\mathrm{x}$-axis. There is a positive correlation between the two figures, though there is also clearly some 
disagreement. In particular, the Pearson correlation is around 0.74 , implying that only around half the variation in teachers' reported working hours using a single question can be explained by reported working hours using multiple questions. As these two sets of reported working hours are based upon two consecutive questions within the same survey, it may be surprising that this correlation is not higher.

Figure 1. The consistency of teachers' reported working hours. Evidence from TALIS 2013.

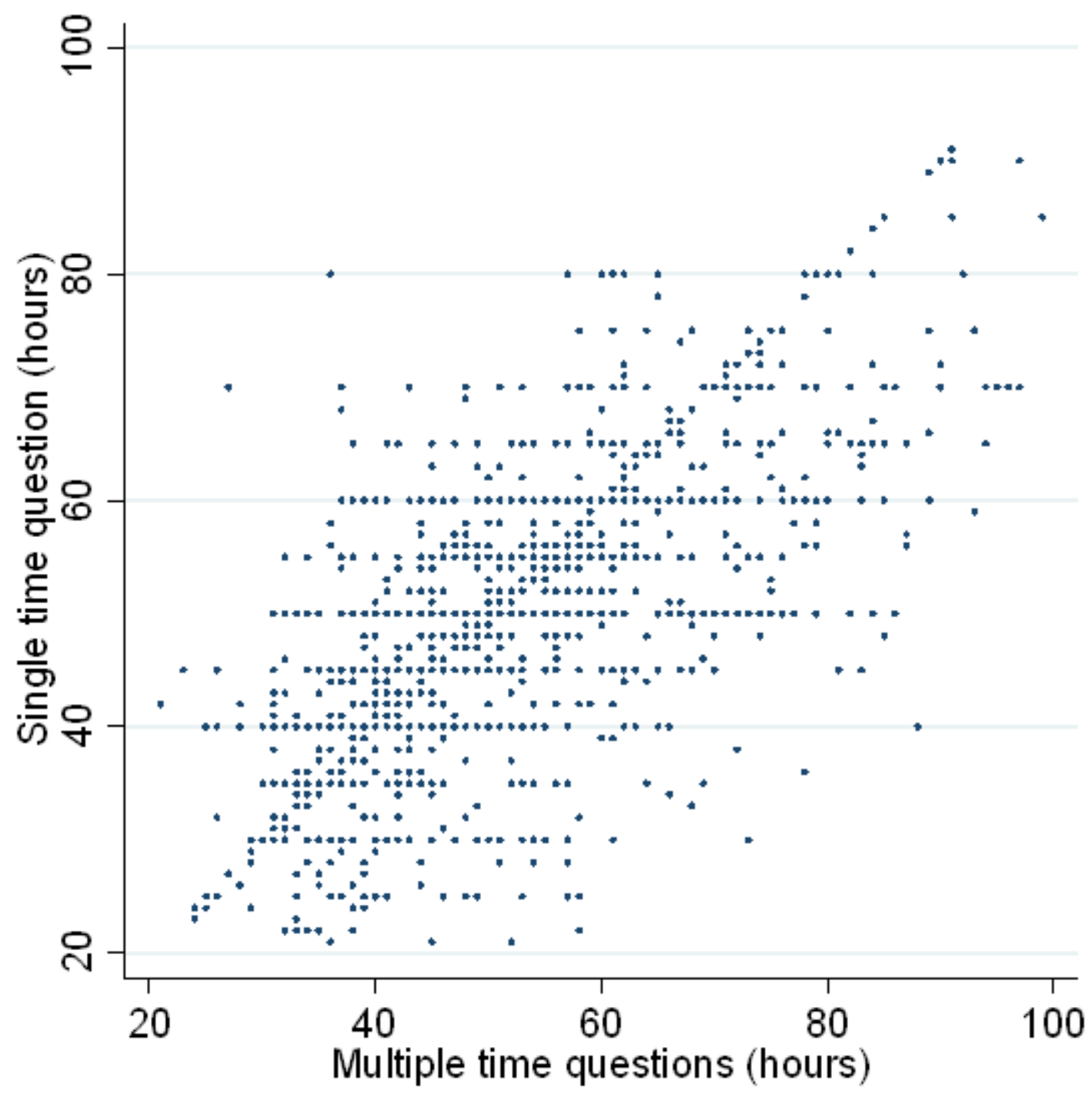

Note: Graph based upon full-time lower-secondary teachers where reported working time using both measures was greater than 20 hours per week and less than 100 hours per week. The Pearson correlation is 0.74 . 
As TALIS is an international survey, it is also possible to investigate the consistency of results at the country level, depending upon whether average working hours is based upon a single or upon multiple questions. These results, based upon TALIS 2018, are presented in Figure 2.

Figure 2. International comparisons of lower-secondary teachers working hours. Consistency of results using two different measures of total working hours.

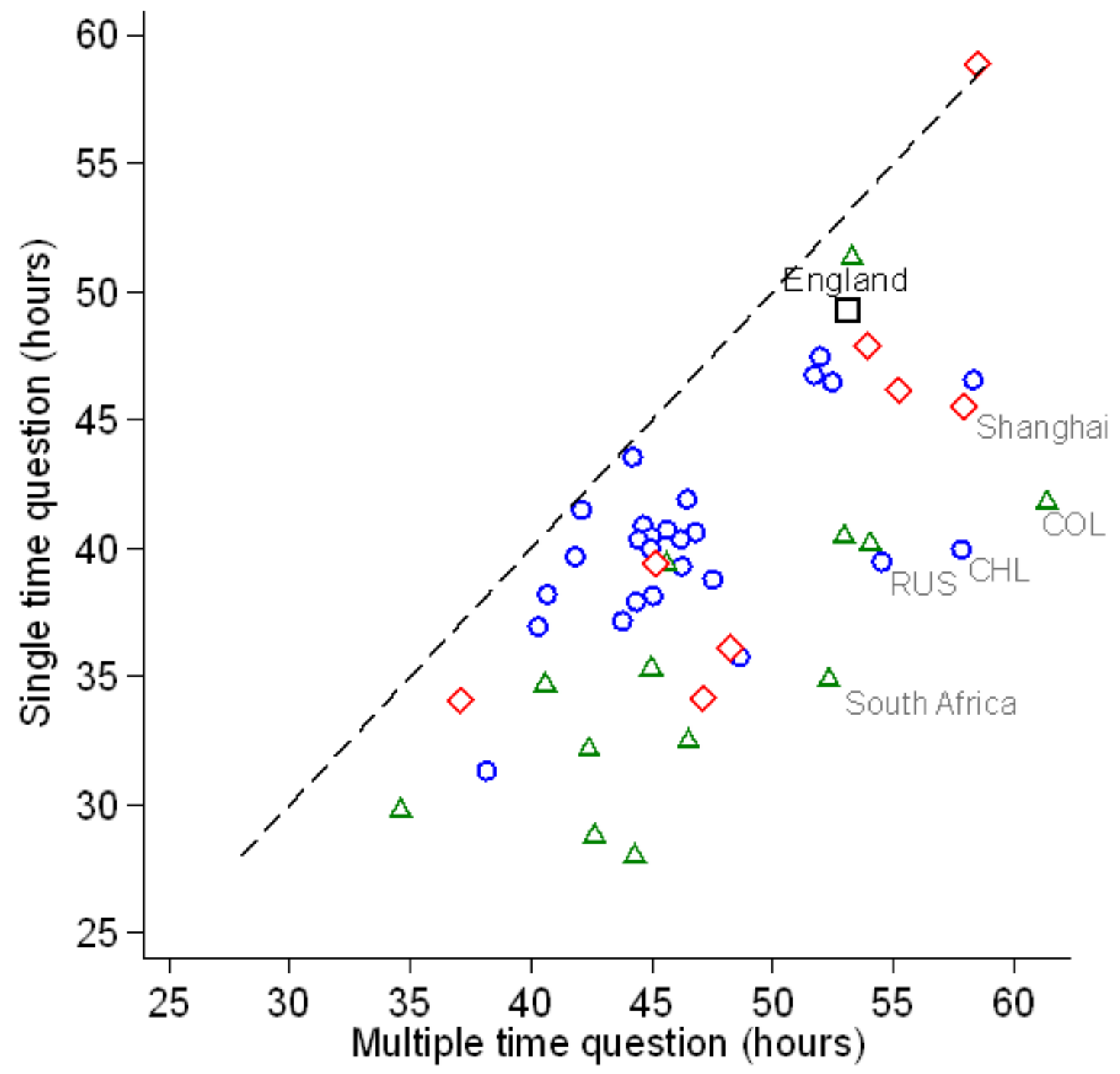

Source: Authors' calculations using TALIS 2018 database. Pearson (Spearman) correlation $=0.66(0.61)$. Red triangles are high-performing PISA countries, green triangles low-performing PISA countries and blue dots countries with performance similar to England. See Jerrim and Sims (2019: Appendix B) for further details about countries have been divided into high/low/average performance groups. OECD average is 41 hours per week when using a single question and 47 hours when using multiple questions. Analogous figures for England are 49 and 53 hours per week. 
From this graph, there are four key points to note. First, in almost every country (except Japan), reported average working hours are higher when derived from multiple questions (as compared to a single question). This is illustrated by the fact that almost every datapoint in Figure 2 sits below the dashed 45-degree line. Second, the cross-country correlation is far from perfect; the Pearson correlation is 0.66 and the Spearman correlation is 0.61 . Third, consequently, the picture of average working hours within a jurisdiction can change quite dramatically depending upon which measure is used. Take Shanghai, for example. The average working week reported by teachers is 46 hours when they are asked in a single question, but 58 hours when this is based upon a measure derived from the time they say they spend upon different work-related tasks. Fourth, England is a country where teachers work long hours, regardless of the measure used. Specifically, the average working week of lower-secondary teachers in England is eight hours longer than the OECD average based upon the single working hours question (49 versus 41 hours per week) and six hours longer when derived from multiple questions (53 versus 47 hours per week).

Figure 3 provides a similar investigation of consistency of teacher reported working hours using the data gathered from Teacher Tapp. This compares weekly working hours gathered using a single question at the end of the week to daily questions asking teachers their working hours (with a weekly total then derived). A similar finding emerges. There is a positive association, although there is also a reasonable amount of disagreement (Pearson $r=0.64$ ). Likewise, Figure 4 uses data from the TUDs to compare working hours on a typical day based upon diary data (x-axis) compared to a measure derived from a single weekly question (y-axis). The correlation we now find is quite weak (Pearson $r=0.40$ ) though only based upon a small sample. 
Figure 3. The correlation between teachers daily working hours when reported using a diary method (horizontal axis) compared to a single question (vertical axis)

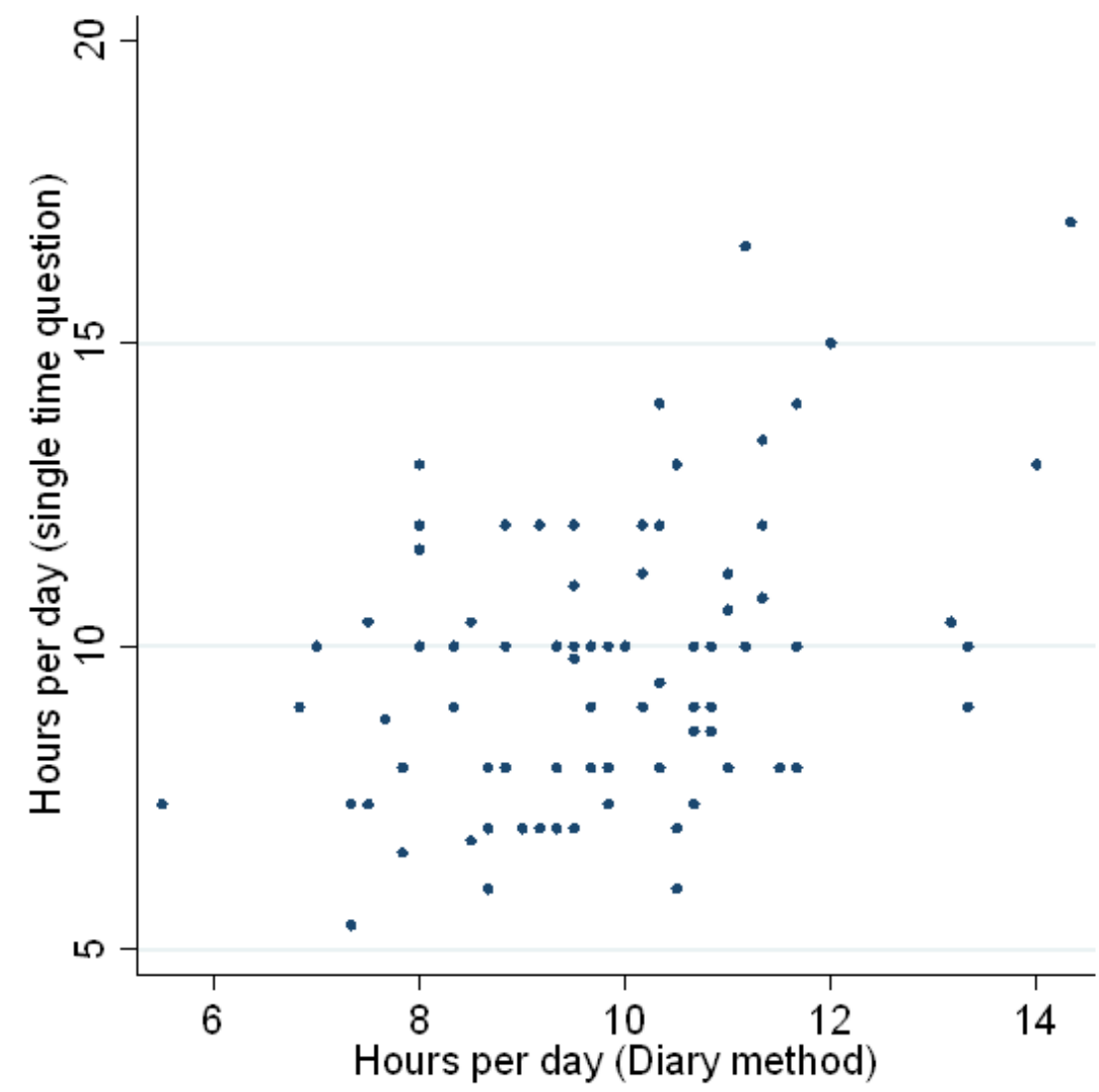

Notes: Analysis based upon 0.40 teachers who participated in the 2014/2015 UK time-use diary study.

Figure 4. The correlation between daily and weekly methods of estimating weekly working hours using Teacher-Tapp

Daily versus weekly log of hours

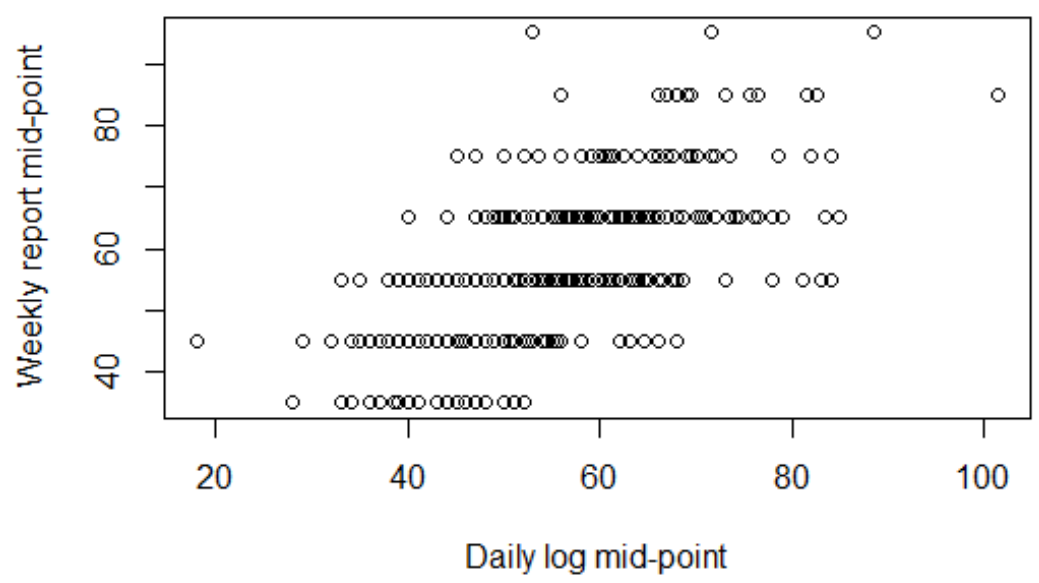

Notes: Analysis based upon 854 teachers who participated in the Teacher-Tapp survey conducted in November 2018. Pearson correlation $=0.64$. 
Table 1 turns to how a set of key descriptive statistics about working hours compares depending upon the measure used. Despite the noise in the data described in the paragraphs above, the distributional figures reported in this table are reasonably consistent. Starting with TALIS, the use of a single question (compared to separate questions for different tasks) leads to an underestimation of weekly working hours in England by around an hour a week. Similar results hold for differences at various points of the distribution (i.e. the $10^{\text {th }}, 25^{\text {th }}, 75^{\text {th }}$ and $90^{\text {th }}$ percentile are all reasonably similar). Similar results also hold within the TUD data, with the average according to the diary data being around 20 minutes higher per day than using just a single question. There are slightly larger differences with respect to the distributional statistics. For instance, there is around 0.7 of an hour difference between the single weekly question and day diary figure at the $10^{\text {th }}$ percentile and 0.8 of an hour difference in the figures for the $25^{\text {th }}$ percentile (which is roughly equivalent to the day diary figures being around 40 minutes higher). This result should be interpreted with caution, however, given the small sample size. Finally, the difference with respect to the Teacher Tapp data is slightly larger (3.4 hours per week), though this may perhaps be expected given the categorical nature of the data that were collected.

Table 1. Differences in descriptive statistics for teachers working hours depending upon the data collection method used

\begin{tabular}{|c|c|c|c|c|c|c|}
\hline & $\begin{array}{r}\text { TAL } \\
(\mathbf{w}\end{array}$ & $\begin{array}{l}2013 \\
\text { xy) }\end{array}$ & $\begin{array}{r}\text { TUDs } \\
\text { (daily }\end{array}$ & $\begin{array}{l}014 / 15 \\
\text { lours) }\end{array}$ & $\begin{array}{r}\text { Teacher- } \\
\text { ' }\end{array}$ & $\begin{array}{l}\text { p. Nov } 2018 . \\
\text { kly) }\end{array}$ \\
\hline & $\begin{array}{c}\text { Single } \\
\text { weekly } \\
\text { question }\end{array}$ & $\begin{array}{l}\text { Questions } \\
\text { for } \\
\text { different } \\
\text { tasks } \\
\end{array}$ & $\begin{array}{c}\text { Single } \\
\text { weekly } \\
\text { question }\end{array}$ & Day diary & $\begin{array}{c}\text { Single } \\
\text { weekly } \\
\text { question }\end{array}$ & $\begin{array}{c}\text { Seven daily } \\
\text { questions }\end{array}$ \\
\hline P10 & 35 & 36 & 7.0 & 7.7 & 46 & 37 \\
\hline $\mathrm{P} 25$ & 42 & 42 & 8.0 & 8.8 & 52 & 44 \\
\hline P50 & 50 & 50 & 9.4 & 9.8 & 55 & 51 \\
\hline P75 & 59 & 60 & 10.6 & 10.7 & 66 & 58 \\
\hline $\mathrm{P} 90$ & 65 & 69 & 12.0 & 11.5 & 74 & 66 \\
\hline Mean & 50.1 & 51.3 & 9.5 & 9.8 & 54 & 51 \\
\hline P90 - P10 & 30 & 33 & 5.0 & 3.8 & 28 & 29 \\
\hline $\mathbf{n}$ & 2,020 & 2,069 & 81 & 81 & 845 & 845 \\
\hline
\end{tabular}

Notes: Figures for TALIS 2013 refer to weekly hours for full-time lower secondary teachers who reported more than 20 hours and less than 100 hours per week. TUD data refers to daily hours for teachers in 2014/15 who were not on leave, working full-time and who worked for five-hours on the diary day in question. Teacher Tapp refers to mid-point of categorical/range responses for panellists working full-time in the week in question. 
What does the above imply for our understanding (and empirical analysis) of teachers' working hours? First, caution should always be exercised when interpreting such data. The most common way of collecting information about working hours is via a single (or multiple) broadbrush question(s) that rely heavily upon respondents' ability to accurately recall a prior working week. This results in a non-trivial degree of measurement error which may affect one's results. Particular caution should be paid to regression models that attempt to investigate the link between working hours and other important outcomes (e.g. teachers' well-being, mental health and decision to leave the profession) given the attenuation bias that this may induce.

Furthermore, there is good reason to believe that capacity to recall last week's working hours will vary across professions, so comparisons of working hours across occupational groups must also be made with care. For example, a receptionist is likely to maintain their contract hours, with little deviation. A hospital nurse would know their allotted shift hours and be able to adjust for times they failed to leave on time. By contrast, the hours that teachers must work (i.e. lesson time) amounts to only about half of their total working hours. And, unlike some other professions, there is no overtime pay and so no need to log working hours.

That said, the results presented in Table 1 suggest that looking at aggregate descriptive statistics using such measures may provide reasonable results. Although the use of such broad questions are unlikely to be sensitive enough to detect quite modest differences (i.e. one should not overinterpret differences of one or two hours per week based upon such measures) they are likely to provide some useful insights into average hours worked per week.

\section{Results}

Trends in total working hours since 1992

Figure 5 begins by presenting long-run trends in full-time teachers' average working hours (1992 - 2018), with results for primary and secondary teachers illustrated using 95 percent confidence intervals. Overall, average working hours of secondary teachers has remained broadly stable over this period. The 95 percent confidence interval typically sits between 46 and 48 hours per week; it only occasionally dips above or below this level. The most notable peak in the average working hours of secondary teachers occurred in 2001, when it reached 49 hours per week. The trough, meanwhile, occurred in 2006 and 2010 when the average was just over 46 hours per week. Nevertheless, the secondary school average has generally remained quite stable (typically within a two-to-three-hour range) over this 25 -year period, with little to 
suggest that the working hours of secondary teachers at the time of writing are outside of their historical norm.

\section{Figure 5. Trends in the average working hours of teachers between 1992 and 2018}

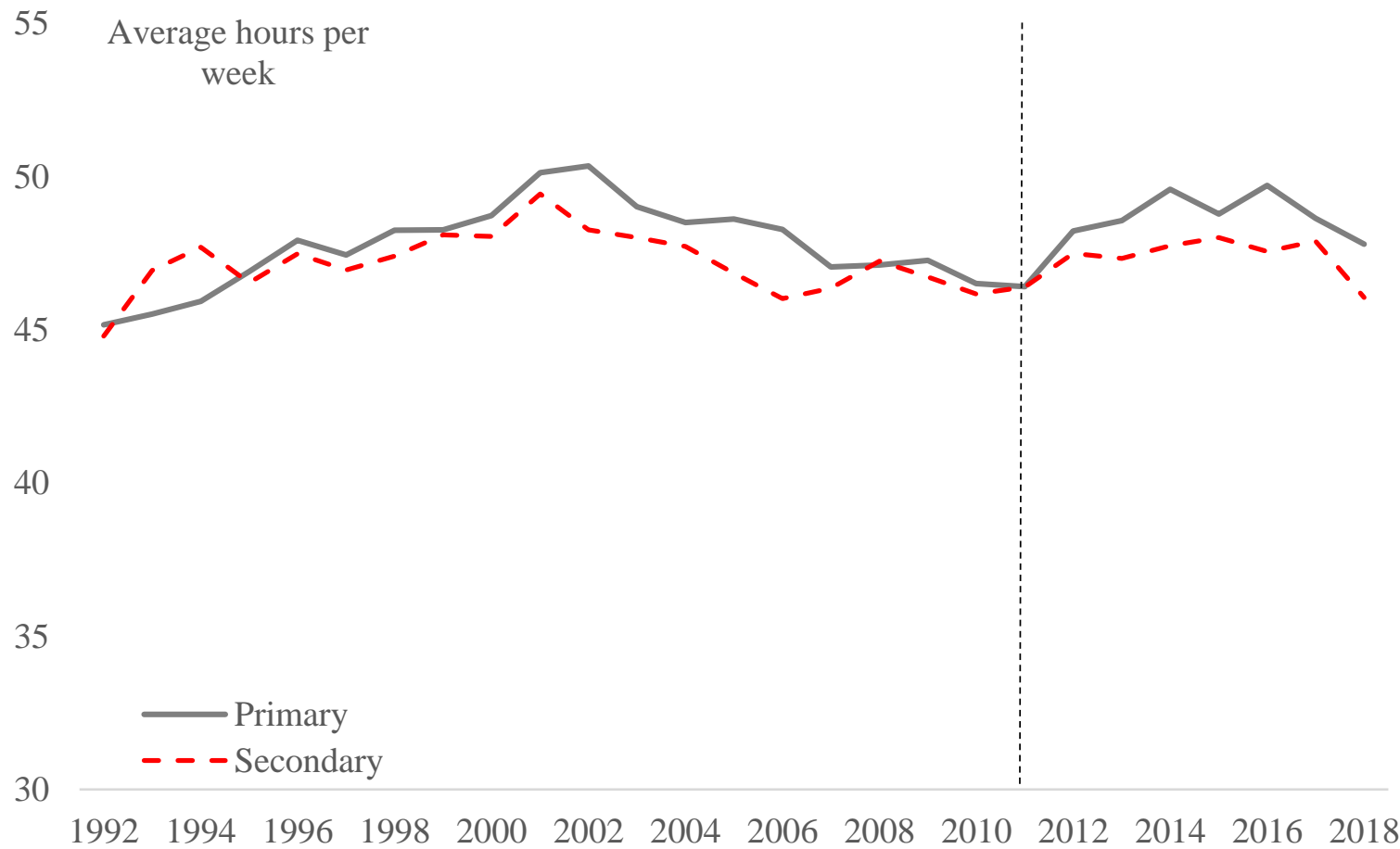

Note: Graph presents the estimated average total working hours of full-time teachers in England (LFS variable TOTHRS). A break in the series has been indicated in 2010 with a dashed line. Prior to 2010, headteachers were included in the definition of primary/secondary teachers within the SOC codes. This changed in 2010, with headteachers separated into a unique category. Source = Quarterly Labour Force Survey.

A broadly similar result holds for primary teachers, although perhaps with slightly more pronounced peaks and troughs. The longest reported average working hours, of 50 hours per week, occurred around 2002, although the period between 2013 and 2017 was just shy of this level (around 49 hours per week). In contrast, the lowest point(s) for primary teachers' average hours was in 1992 (46 hours per week) and around 2010 (approximately 47 hours per week). However, it is the broad stability of the reported average hours that really stands out. Over the past 25 years, full-time primary teachers have worked (on average) somewhere between 47 and 49 hours per week, without any substantial change to this figure.

Table 2 provides some additional context to this result, drawing on the much smaller scale TUD data from 2000/01 and 2014/15. Panel (a) refers to daily hours spent at work on a typical weekday and at the weekend. This again suggests that there has been little change in average working hours over this period. The point estimate for the average (mean) during the week has decreased slightly (9.7 hours per day in 2000/01 to 9.3 hours in 2014/15) and increased slightly 
at weekends ( 0.9 to 1.7 hours) but, given the small sample sizes, one should not read too much into these relatively minor differences.

Table 2. The working hours of full-time teachers on a typical day. Evidence from the UK Time-Use Diary Survey

(a) Daily hours at work

\begin{tabular}{lcccc}
\hline & \multicolumn{2}{c}{ Typical weekday } & \multicolumn{2}{c}{ Typical Saturday/Sunday } \\
\hline & $\mathbf{2 0 0 0 / 0 1}$ & $\mathbf{2 0 1 4 / 1 5}$ & $\mathbf{2 0 0 0 / 0 1}$ & $\mathbf{2 0 1 4 / 1 5}$ \\
\hline P10 & 7.8 & 7.2 & 0 & 0 \\
P25 & 8.5 & 8.2 & 0 & 0 \\
P50 & 9.7 & 9.3 & 0 & 0 \\
P75 & 11.0 & 10.3 & 1.5 & 3 \\
P90 & 12.3 & 11.3 & 3.5 & 5.3 \\
\hline Mean & 9.7 & 9.3 & 0.9 & 1.7 \\
P90 - P10 & 4.5 & 4.2 & 3.5 & 5.3 \\
\hline n & $\mathbf{9 0}$ & $\mathbf{8 9}$ & $\mathbf{1 1 9}$ & $\mathbf{6 0}$ \\
\hline
\end{tabular}

(b) Daily hours in selected other activities

\begin{tabular}{lcccccccc}
\hline & Travel to/from work & \multicolumn{2}{c}{ Home chores } & \multicolumn{2}{c}{ Family care } & \multicolumn{2}{c}{ Voluntary work } \\
& $\mathbf{2 0 0 0 / 0 1}$ & $\mathbf{2 0 1 4 / 1 5}$ & $\mathbf{2 0 0 0 / 0 1}$ & $\mathbf{2 0 1 4 / 1 5}$ & $\mathbf{2 0 0 0 / 0 1}$ & $\mathbf{2 0 1 4 / 1 5}$ & $\mathbf{2 0 0 0 / 0 1}$ & $\mathbf{2 0 1 4 / 1 5}$ \\
\hline P10 & 0.3 & 0.3 & 0.2 & 0.2 & 0.0 & 0.0 & 0.0 & 0.0 \\
P25 & 0.3 & 0.5 & 0.7 & 0.5 & 0.0 & 0.0 & 0.0 & 0.0 \\
P50 & 0.5 & 0.8 & 1.2 & 1.2 & 0.0 & 0.0 & 0.0 & 0.0 \\
P75 & 1.0 & 1.2 & 2.0 & 1.8 & 0.0 & 0.0 & 0.0 & 0.0 \\
P90 & 1.5 & 1.7 & 3.2 & 2.5 & 0.7 & 1.7 & 0.0 & 1.0 \\
\hline Mean & 0.7 & 0.9 & 1.5 & 1.2 & 0.2 & 0.4 & 0.0 & 0.2 \\
P90-P10 & 1.2 & 1.3 & 3.0 & 2.3 & 0.7 & 1.7 & 0.0 & 1.0 \\
\hline N & $\mathbf{9 0}$ & $\mathbf{8 9}$ & $\mathbf{9 0}$ & $\mathbf{8 9}$ & $\mathbf{9 0}$ & $\mathbf{8 9}$ & $\mathbf{9 0}$ & $\mathbf{8 9}$ \\
\hline
\end{tabular}

Notes: Hours at work includes hours in either main or secondary activity. Hours relate to full-time teachers who were not on holiday/sick leave, who reported that it represented a "typical" day and who reported working at some point during that day. Weekend hours based upon term-time weeks only. Figures in panel (a) do not include breaks or time spent travelling to work.

Panel (b) provides further details on other types of work (e.g. commuting time, family responsibilities) that may also put time pressure upon teachers' lives. Again, these results seem to reveal little change over time. The average time teachers spend upon travelling to work, home chores, family care and voluntary work in 2014/15 is similar to in 2000/01 (values have typically moved 10 to 15 minutes in either direction). These differences are not large or statistically significant and hence provide further evidence of a broadly stable picture over time. 
Trends in time devoted to different tasks. 2013 to 2018

Using the TALIS 2013 and 2018 datasets for England, we can also explore the average time that lower secondary teachers spend upon different tasks. Although data are only available over a short five-year time horizon, and relate only to lower-secondary teachers, it is important that we document whether any change has emerged in specific areas e.g. marking, planning, administration.

Table 3. Change in the average amount of time full-time lower-secondary teachers in England spend upon different tasks between 2013 and 2018

\begin{tabular}{|l|c|c|}
\hline & $\mathbf{2 0 1 3}$ & $\mathbf{2 0 1 8}$ \\
\hline Teaching & 20.3 & 20.5 \\
\hline Planning /preparation & 8.0 & 7.5 \\
\hline Teamworking & 3.5 & 3.2 \\
\hline Marking & 6.3 & 6.3 \\
\hline Pupil guidance/discipline & 1.8 & 2.7 \\
\hline Management & 2.4 & 2.3 \\
\hline Administration & 4.2 & 4.0 \\
\hline Talking to parents & 1.6 & 1.6 \\
\hline Extracurricular activities & 2.2 & 1.7 \\
\hline Other & 2.4 & 3.4 \\
\hline Total non-teaching tasks & $\mathbf{3 2 . 5}$ & $\mathbf{3 2 . 7}$ \\
\hline Ratio teaching:non-teaching & $\mathbf{0 . 6 2}$ & $\mathbf{0 . 6 3}$ \\
\hline
\end{tabular}

Notes: TALIS 2013 and 2018 databases. Figures refer to average working hours per week during term-time.

Table 3 suggests that the working hours of lower-secondary teachers remained stable between 2013 and 2018. Average hours spent teaching (20.3 versus 20.5 hours) and time spent upon non-teaching tasks (32.5 versus 32.7 hours) were virtually unchanged. Critically, there was little sign of any substantial reduction in marking (6.3 hours per week in both 2013 and 2018) and administration (4.2 hours in 2013 and 4.0 hours in 2018); two aspects of their job that teachers particularly dislike (Jerrim \& Sims, 2019). Moreover, any minor reductions observed for lesson planning/preparation and extracurricular activities (both half an hour lower per week in 2018 than in 2013) has been offset by increases in pupil guidance/discipline and "other" (undefined) tasks.

Variation during the academic year and working during holidays

The amount that teachers work per week could vary substantially over the academic year. Figure 6 provides, to our knowledge, the first evidence on this issue for England based upon the Labour Force Survey. 


\section{Figure 6. Variation in teachers' working hours over the year}

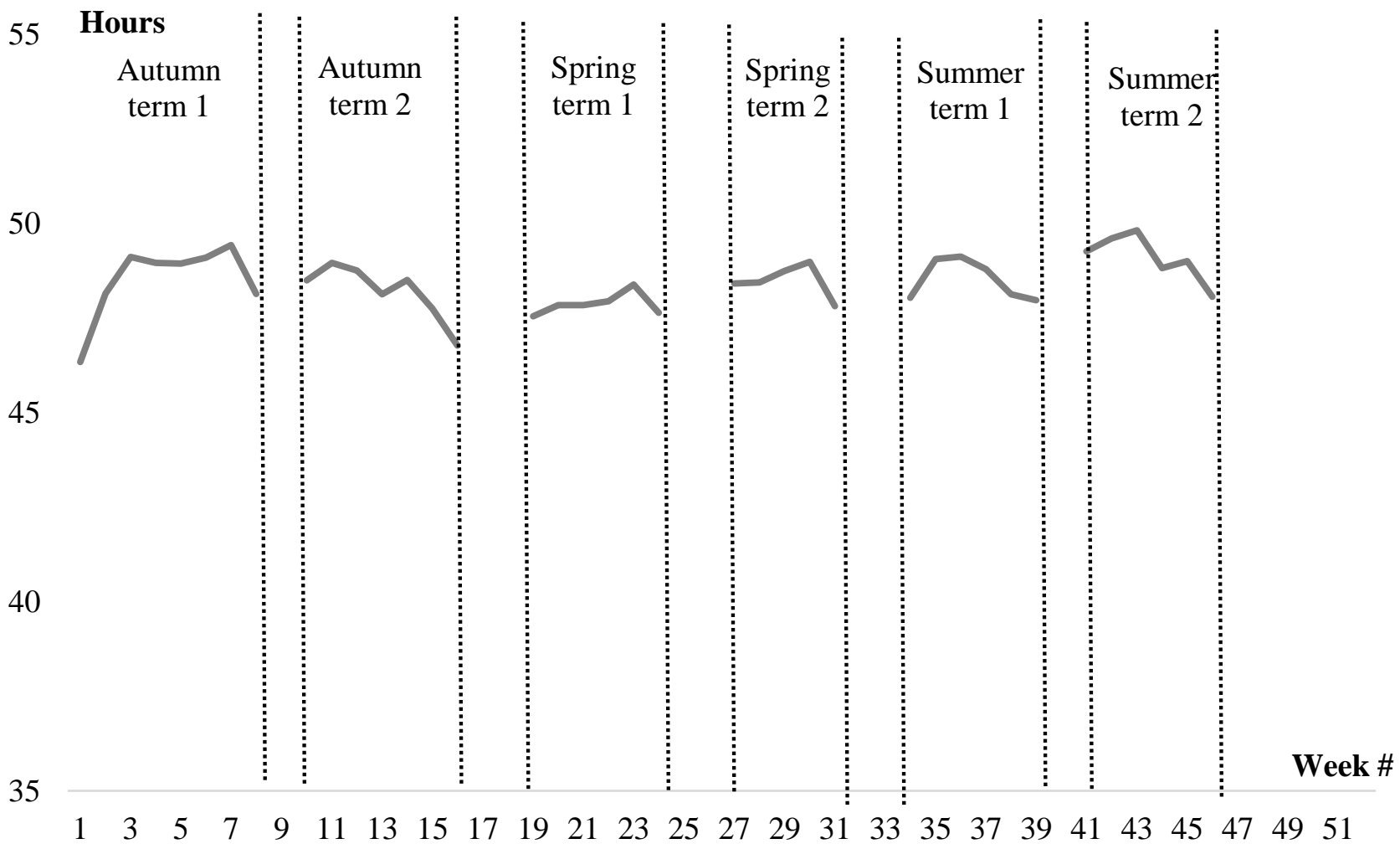

Note: Figures refer to full-time teachers who were not proxy respondents, not on parental leave, not on a training course, not sick or injured during the survey week, not changed their job, was not affected by poor weather or labour dispute during the survey week. Includes primary, secondary, SEN and headteachers. Sample also restricted to those teachers who reported not working abnormal hours due to being on leave/holiday and who worked for at least 20 hours in the reference week. Major school holiday weeks have been excluded. Source = Quarterly Labour Force Survey pooled between winter 1996 and winter 2018.

Interestingly, differences in average working hours of full-time teachers over the academic year do not seem to be particularly large. Indeed, within Figure 6 there is no particular period where they are notably above or below the average. Nevertheless, a couple of interesting features do stand out. First, the average starts at a comparatively high point during the autumn term $(\approx 49$ hours per week) before dipping to a low of $\approx 48$ hours per week in the half-term following the Christmas break. Average working hours then increase steadily to reach almost 50 hours per week at the start of the second summer half-term (coincides with the timing of end-of-year testing and national examinations in England). However, we again stress the broadly stable nature of teachers' self-reported working hours, keeping within a two-hour range throughout the academic year. The second feature of note from Figure 6 is that working hours tend to dropoff a little towards the end of each term. This is most apparent in the build-up to Christmas, with average hours at the start of the second Autumn term being around two hours higher than at the end of the term ( 49 versus 47 hours per week). A similar result emerges during the half- 
term preceding the summer holidays (the average is around 50 hours at the start of the second summer term compared to 48 hours at the end $)^{5}$.

The LFS data also allow us to explore how many hours teachers report working during the school holidays. This is important as most existing analyses of teachers' working hours have only asked about hours worked during the term. Results are presented in Table 4.

Table 4. The number of hours per week teachers report working during school holidays

\begin{tabular}{lcccccc}
\hline & $\begin{array}{c}\text { October } \\
\text { half term }\end{array}$ & $\begin{array}{c}\text { Christmas } \\
\text { holidays }\end{array}$ & $\begin{array}{c}\text { February } \\
\text { half term }\end{array}$ & $\begin{array}{c}\text { Easter } \\
\text { holidays }\end{array}$ & $\begin{array}{c}\text { Summer } \\
\text { half term }\end{array}$ & $\begin{array}{c}\text { Summer } \\
\text { holidays }\end{array}$ \\
\hline 10th percentile & 0 & 0 & 0 & 0 & 0 & 0 \\
25th percentile & 0 & 0 & 0 & 0 & 0 & 0 \\
Median & 0 & 0 & 0 & 0 & 0 & 0 \\
75th percentile & 0 & 0 & 0 & 0 & 4 & 0 \\
90th percentile & 20 & 15 & 12 & 18 & 30 & 7 \\
\hline Mean & 4.1 & 3.0 & 3.3 & 4.0 & 6.9 & 2.4 \\
Observations & $\mathbf{8 2 0}$ & $\mathbf{1 , 6 8 4}$ & $\mathbf{6 3 3}$ & $\mathbf{1 , 9 0 5}$ & $\mathbf{4 1 9}$ & $\mathbf{5 , 3 4 9}$ \\
\hline
\end{tabular}

Note: Figures refer to full-time teachers who were not proxy respondents, not on parental leave, not on a training course, not sick or injured during the survey week, not changed their job, not affected by poor weather or labour dispute during the survey week. Sample also restricted to those teachers who reported working different hours to normal due to being on leave/holiday. Source = Quarterly Labour Force Survey pooled between winter 1996 and winter 2018.

The first key finding from Table 4 is that the median teacher reports working zero hours during the school holidays. Most full-time teachers manage to give themselves a break from work. However, this masks the fact that some staff continue to report working long hours even when they are on holiday. For instance, figures for the $90^{\text {th }}$ percentile of the working hours distribution suggest that ten percent of full-time teachers work at least 20 hours per week during the October half-term, 15 hours per week over Christmas, 18 hours per week over Easter and 30 hours per week over the summer half-term. In other words, the distribution of working hours during school holidays is strongly positively skewed, with a sub-section of the profession continuing to put in very long hours during the school break. This hence drives the average (mean) up. Consequently, the average (mean) sits at around four hours of work per week for teachers during most school holidays, with the figure being slightly higher during the final halfterm of the academic year $(\approx 7$ hours per week) and lower during the summer $(\approx 2.5$ hours per week).

\footnotetext{
${ }^{5}$ This result is not due to teachers being on holiday or leave, as we have excluded this group from the sample
} 
However, responses to Teacher Tapp questions (not reported in tabular form) paint a rather different picture. During a single (summer) half-term holiday, this panel of teachers were asked about the type of work-related activities they had completed. Around 6-in-10 said that they read something relevant to their job, 6-in-10 reported planning curriculum or lessons, one-third reported marking students work, 9 percent said they ran an exam revision session for students and 4 percent reported attending a work-related workshop or course. Consequently, the current available evidence on teachers' working hours during school holiday is somewhat contradictory.

\section{Working in the evening and weekends}

Of course, teachers may also work unsociable hours during term-time, including in the evenings and at weekends. Again, little is currently known about this issue. Hence Figure 7 draws upon data from the LFS which, since 2005, has asked respondents whether they "usually" work in the evening, at nights and during the weekend. Our interpretation of this question - particularly the term "usually" - is that teachers report working at such times more often than not.

\section{Figure 7. The proportion of teachers who report that it is "usual" for them to work in the evening, at night and at weekends}

$50 \% \%$ of teachers

$40 \%$

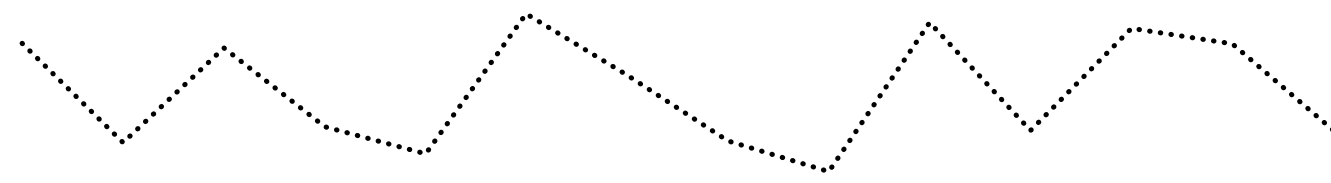

$30 \%$

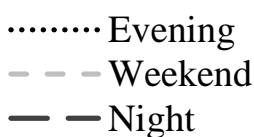

$20 \%$

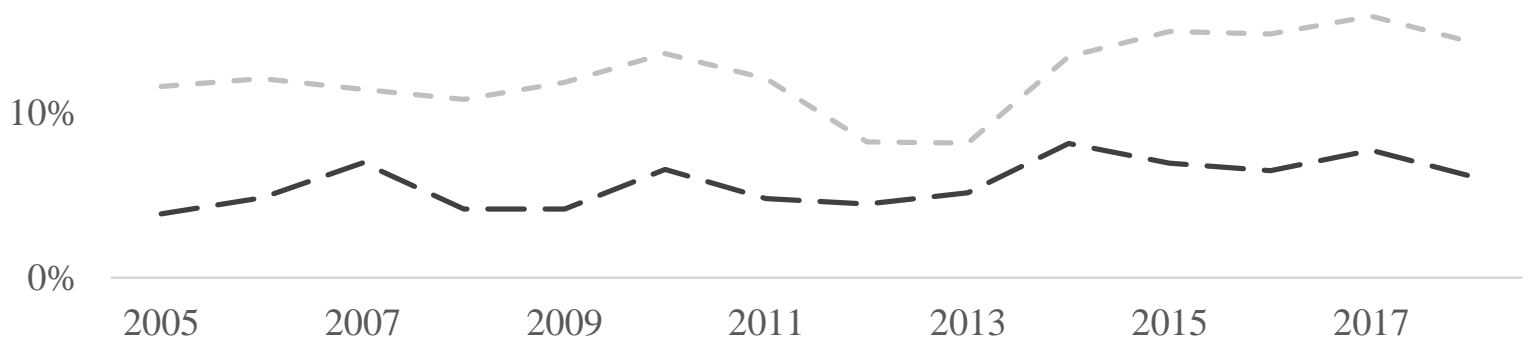

Notes: Graph presents the percentage of teachers who say that they usually work in the evening, at weekends and at night. Source $=$ Quarterly Labour Force Survey. The sample is comprised of full-time primary teachers, secondary teachers, SEN teachers and headteachers. In additional analysis we have experimented with repeating the analysis for primary and secondary teachers separately and obtained similar results. 
Around 40 percent of teachers indicate that they usually work in the evening, with around seven percent suggesting that they frequently work at night ${ }^{6}$. This helps to illustrate how a substantial proportion of teachers in England take their work home with them and continue to put in extra hours long after the school gates have shut. Similarly, around one-in-ten teachers indicate that they usually work at the weekend. Moreover, consistent with evidence presented in previous sub-sections, there is no clear evidence of change in the proportion of teachers working weekend/evening/night over time.

Figure 8 provides further detail on this issue, drawing upon the 2000/01 and 2014/15 TUDs. This provides the percentage of teachers who said they were working (as either their primary or secondary activity) over a 24-hour-period during a usual working day. This thus helps one to visualise a "typical" working day for a school teacher in England. It can be broadly described as follows.

\section{Figure 8. The proportion of teachers working at different times in the school day}

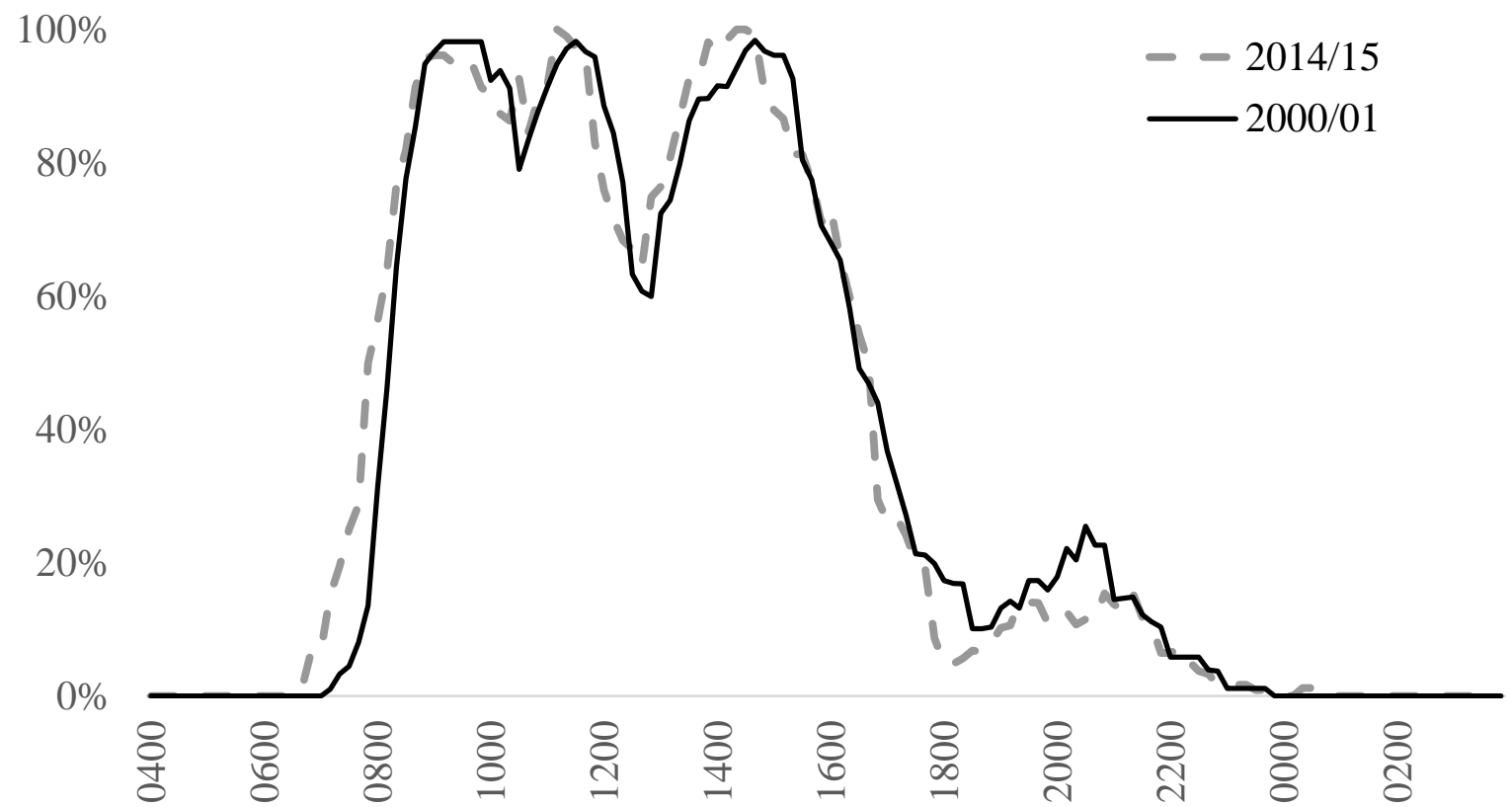

Notes: Figures based upon the 2000/01 (black solid lines) and 2014/15 (grey dashed lines) UK Time-Use Diaries. Data based upon 89 observations in 2000/01 and 90 observations in 2014/15. Figures refer to refer to full-time teachers who were not on holiday/sick leave, who reported that it represented a "typical" day and who reported working at some point during that day. Time spent travelling to work and breaks not included.

The average full-time teacher will have arrived at school and started work by around 0800 (with almost all teachers having started by 0830). The vast majority will then work through

\footnotetext{
${ }^{6}$ Participants were asked: "within your regular pattern of work is it usual for you to work (a) during the day; (b) during the evening; (c) at night" - selecting all that apply.
} 
until at least midday without a break. A dip in the series presented in Figure 8 can then be observed between 1200 and 1330, when some teachers are able to take a break from work. Note, however, that this dip in the percentage of teachers who say they are working is relatively modest. This, in turn, implies that many teachers are likely to be working during their lunch break and only taking short amounts of time to completely switch off. Almost all teachers then work between 1330 and 1530, after which a number start to finish for the day. Most teachers then leave school somewhere between 1530 and 1730, with almost everyone having left by 1800. However, for a significant minority of teachers, their work is not yet done for the day. Another spike in the proportion of teachers who report working emerges between 1900 and 2100, with around one-in-five saying that they are working at any given 15-minute timeslot during this period. By around 2230, almost all teachers have finished for the day, with the first teachers starting to return the next day around 0700 .

The other notable feature of Figure 8 is that it suggests there has been little change to the pattern of teachers' working hours over time. Although sample sizes are small, estimates from the 2000/01 and 2014/15 TUDs are quite similar, with there being no obvious change over this 15 year period.

Teacher Tapp responses (not reported in tabular form) help us understand the nature of teacher's lunch time. Lunch breaks are often short. For 8 percent of teachers they are less than 30 minutes long, while for 29 percent they are 30-44 minutes. A minority has a lunch break of one hour or longer. This is consistent with other recent research, which has found break times at schools are getting shorter (Baines \& Blatchford 2019). Around one-in-eight teachers run a lunchtime club all year round (with many more running one for part of the year). During their lunchbreak, teachers do the things we might expect (e.g. eating, visiting bathroom, talking to colleagues) but also work-related activities (68 percent read emails, 40 percent create resources, 55 percent tidy their classroom). This role of the lunchbreak as a rare time without a class to teach emphasises how different it is to lunchbreaks in many other professions. In particular, it does not allow time for teachers to switch-off, with many continuing to work in some form.

Responses from Teacher Tapp questions also highlight how hard it is for teachers to measure their typical after-school activities. Whilst one-in-five run an after-school club all year round, a greater proportion say they do so but for only part of the year. For one week in May 2018, just 5 percent said that they had no after-school meetings or activities that week. The 
proportions staying late once, twice, three-times, four-times and five-times in the week were 20 percent, 37 percent, 23 percent, 10 percent and 6 percent, respectively. Once at home, on a particular night in April 2018, 39 percent of teachers said they planned or marked whilst the television was on.

\section{Discussion and conclusion}

This research set out to provide a more comprehensive assessment of teachers' working hours in England. Drawing on four different datasets, it has given a detailed account of the levels, structure and changes in teachers' working hours.

Teachers in England work long hours. Representative survey data suggest that the median teacher works a fifty-hour week, with time use diary data showing that they put in just under ten hours on a typical weekday. A quarter of teachers work more than 59 hours a week, putting in 10.7 hours on the average weekday. Remarkably, one in ten teachers works more than 65 hours per week. Around $40 \%$ of teachers report that they 'usually' work in the evening, 10\% at the weekend and 7\% at night. Working hours for teachers in England are higher than almost all other countries for which comparisons can be made and are 8 hours (one working day) per week longer than the OECD average. The finding that teachers work long hours in England is consistent with prior research (Deakin et al., 2010; Kodz et al., 2003; Micklewright et al., 2014; Worth et al 2018; Ofsted 2019; Jerrim and Sims 2019). However, it is notable that all of our estimates of total hours are lower than those from both the 2013 (55.7-59.3 hours per week) and the 2016 (53.5-55.5 hours per week) government workload surveys (TNS-BMRB, 2014; Higton et al., 2017).

Although teachers work (on average) long hours, we did not find evidence that it has increased in recent years. Indeed, total working hours as measured in the Labour Force Survey have remained relatively stable - between 46 and 48 hours per week - over the last twenty years. Similarly, the proportion of teachers who report that they 'usually' work evenings and weekends has also been broadly stable since 2005 . There has also very little change in the number of hours teachers report spending on specific tasks between 2013 and 2018, with teachers spending around 8 hours per week on marking, 6 hours per week on planning and 4 hours per week on administration in both years. 
Our finding that working hours have not noticeably increased stands in contrast to those from the 2010, 2013 and 2016 government workload surveys ${ }^{7}$, which recorded a sizable increase in total working hours since 2010, albeit with caveats about changes in the methodology used across survey sweeps (Deakin et al., 2010; TNS-BMRB, 2014; Higton et al., 2017). It also stands in contrast to the prevailing policy consensus that improving teacher retention requires making the job "manageable again" (DfE, 2019b, p 4). How do we explain these discrepancies?

One possibility is that differences in the way working hours are recorded across survey sweeps has painted a misleading picture. For example, we show in Section 3 that asking the same question in different ways leads to different estimates of working hours. It is also known that measuring teacher working hours using a diary method provides different results to asking respondents to retrospectively estimate their working hours (West, 2014). However, in our view, a far more plausible explanation for the discrepancy is response rates. The 2010, 2013 and 2016 Department for Education workload surveys all randomly sampled teachers but achieved vastly different response rates of $57 \%, 15 \%$ and $34 \%$, respectively. The data from 2013 and 2016 surveys therefore cannot be considered to be representative of the teaching workforce as a whole and differences in estimates of total working hours between the 2010 and 2013/2016 surveys may simply reflect changes in the types of teachers that responded across surveys. By contrast, the LFS and TALIS data employed in the present paper are derived from surveys achieving response rates of $60-70 \%$ and $83-85 \%$, respectively. They are therefore far more likely to accurately and consistently reflect changes across the teaching workforce.

What, then, does this paper imply for education policy in England? Perhaps most importantly, our findings show that five years of policy initiatives - implemented by three separate Secretaries of State for Education - have so far proven insufficient for achieving a reduction in the total number of hours worked by teachers. Reducing working hours to bring them into line with international norms will therefore likely require additional, more radical action on the part of policymakers. Indeed, our research reveals that working hours have been at the present high levels for many years, which suggests perhaps that they will be more difficult to shift than previously anticipated.

\footnotetext{
${ }^{7}$ These are the Department for Education's own teacher workload surveys that they have conducted at various points over the last decade. We do not analyse these data within this paper, as we believe that they have significant limitations, particularly with respect to comparability over time (as discussed below).
} 
More broadly, our findings suggest that an increase in total working hours are unlikely to explain the widely-reported decline in teacher retention in England. This is for the simple reason that total working hours have not increased very much, particularly among secondary teachers, where the decline in teacher retention has been most marked (Sims, 2018a). Changes in the composition of working hours after 2013 are also very unlikely to be the cause of declining teacher retention, for the same reason. We cannot, however, rule out the possibility that changes in the composition of working hours occurring prior to 2013 are to blame.

In any case, these findings suggest that workload may have been given undue emphasis in the debate on teacher retention. For instance, See and Gorard (2019) argue that issues with declining teacher retention may be due to conflicting and uncoordinated government policies, with increasing focus upon accountability measures and school inspections putting pressure upon school leaders to demand teachers achieve particular results, which in turn has a negative impact upon teachers' motivation and job satisfaction. Improving working environment and school leaderships have also been cited as important factors in retention (Fulbeck 2014; Waters-Weller 2009; Goldhaber et al. 2010). Policymakers might therefore be better off focusing on other, better evidenced approaches to improving retention, such as increasing teacher pay, improving school leadership and improving working conditions (Bueno \& Sass, 2018; Feng \& Sass, 2018; Sims, 2018b; Kraft, Marinell, \& Yee, 2018; Jacob et al., 2015).

The Department for Education have committed to producing robust evidence on teacher workload bi-annually. We support this, but believe that the government's workload survey should be reformed. The response rates are low and the absence of diary method data collection means it adds little value over other routinely collected data sources (e.g. TALIS and the LFS). Our suggestion is therefore that the Department for Education's workload survey be revised so that a truly representative sample of teachers complete time-use diaries. This will, no doubt, be relatively costly and require close co-operation and buy-in from across the sector (particularly teacher unions). Yet the experience of other countries has shown that this is possible (e.g. a large, representative sample of teachers have recently completed TUDs as part of a recent study in Belgium) and our empirical analysis of a small sample of TUDs completed by teachers in the UK illustrate the interesting insights that such data can provide. Collection of such diaries would likely lead to an appreciable increase in data quality, while also greatly enhancing our understanding of the broader lives (and commitments) of teachers. 
The results presented here should, of course, be interpreted in light of the limitations of this study. First, a common theme running throughout this paper has been data quality. Although response rates to the surveys we have analysed are reasonable, we have concerns about the accuracy of the working hours reported. Indeed, our empirical analysis of various datasets illustrates how the internal consistency of reported working hours can be quite poor. This issue stems from the broad nature of the questions asked (e.g. total working hours gathered in a single question) and the measurement error introduced by having to recall quite detailed information from a prior working week. Second, the TALIS dataset we analyse refers to lower-secondary (Key Stage 3) teachers in England; it is possible (though we believe unlikely) that those working in upper secondary schools may have experienced greater change over time in their working hours given that they are faced with preparing pupils for high-stakes GCSE examinations. Third, although our analysis has provided important new detail in places (e.g. how working hours vary over the academic year) many gaps in our knowledge remain. For instance, the evidence we have presented on teachers' working hours during school holidays has been somewhat contradictory, with 60 percent of Teacher-Tapp respondents reporting doing lesson planning and preparation during half-terms, while the median teacher in Labour Force Survey results reported working (during school holidays) zero hours per week. We believe that this issue of working during school holidays is the biggest remaining gap in the evidence base and is a critical aspect of teachers' working lives that the Department for Education needs to better understand. Likewise, further evidence is needed on other aspects of teachers' lives, including other commitments such as child/family care and work around the house. Such additional time commitments, on-top of a busy professional life, have the potential to add significantly to the burden placed upon teachers.

Finally, this paper has focused specifically upon teachers' working hours. This may be different to their total workload, which also includes unfinished tasks that teachers do not find the time to do. While we show the former has been broadly stable over the last 25 years, the latter could have fluctuated more over time. It is arguably such uncompleted tasks that causes the teachers the most stress and end up driving them out of the profession. Our specific focus upon working hours - rather than workload - should be taken into account when interpreting our results.

\section{References}

Allen, R. and McInerney, L. (2019). Does money matter to teachers? Accessed 22/05/2019 from https://teachertapp.co.uk/2019/01/does-money-matter-to-teachers/ 
Artazcoz, L., Cortès, I., Escribà-Agüir, V., Cascant, L., \& Villegas, R. (2009). Understanding the relationship of long working hours with health status and health-related behaviours. Journal of Epidemiology \& Community Health, 63(7), 521-527.

Afonso P., Fonseca M. \& Pires J. F. (2017). Impact of Working Hours on Sleep and Mental Health, Occupational Medicine, 67(5), 377- 382.

Angrave, D., \& Charlwood, A. (2015). What is the Relationship between Long Working Hours, Overemployment, Under-Employment and Subjective Well-Being of Workers? Longitudinal Evidence from the UK. Human Relations, 68(9), 1491-1515.

Baines, D. \& Blatchford, P. 2019. School break and lunch times and young people's social lives: a follow-up national study. Nuffield Foundation report. Accessed 31/07/2019 from

https://www.nuffieldfoundation.org/sites/default/files/files/Baines\%2042402\%20Brea ktimeSurvey\%20-\%20Main\%20public\%20report\%20(May19)-Final(1).pdf

Bambra, C., Whitehead, M., Sowden, A., Akers, J., \& Petticrew, M. (2008). “A hard day's night?" The effects of Compressed Working Week interventions on the health and work-life balance of shift workers: a systematic review. Journal of Epidemiology \& Community Health, 62(9), 764-777.

Bueno, C., \& Sass, T. R. (2018). The Effects of Differential Pay on Teacher Recruitment, Retention and Quality (Working Paper). Available from: http://sites.gsu. edu/cbueno1/files/2014/02/The-Effects-of-Differential-Pay-on-Teacher-Recruitment9b-plus-abstract-2bj1269.pdf

Collewet, M., \& Sauermann, J. (2017). Working hours and productivity. Labour Economics, 47, 96-106.

Deakin, G., James, N., Tickner, M., \& Tidswell, J. (2010). Teachers' workload diary survey 2010 (Research Report DfE-RR057). London: Department for Education.

Demerouti, E., Bakker, A. B., Geurts, S. A., \& Taris, T. W. (2009). Daily recovery from workrelated effort during non-work time. In Current perspectives on job-stress recovery (pp. 85-123). Emerald Group Publishing Limited.

Department for Education [DfE] (2017). Protocol for changes to accountability, curriculum and qualifications. Accessed 22/05/2019 from https://assets.publishing.service.gov.uk/government/uploads/system/uploads/attachme nt_data/file/594215/DfE_Protocol___Feb_2017.pdf

Department for Education (2018a). Factors affecting teacher retention: Qualitative investigation. Accessed 05/07/2019 from https://assets.publishing.service.gov.uk/government/uploads/system/uploads/attachme nt_data/file/686947/Factors_affecting teacher_retention_qualitative_investigation.pdf

Department for Education (2018b). Mapping professional development for reducing teacher workload. Accessed 22/05/2019 from

https://www.gov.uk/government/publications/mapping-professional-development-forreducing-teacher-workload

Department for Education (2019a). Supporting governing boards and trustees: reducing teacher workload. Accessed 22/05/2019 from https://www.gov.uk/government/publications/supporting-governing-boards-andtrustees-reducing-teacher-workload

Department for Education (2019b). Teacher recruitment and retention strategy. Accessed 07/07/2019 from https://assets.publishing.service.gov.uk/government/uploads/system/uploads/attachme nt_data/file/786856/DFE_Teacher_Retention_Strategy_Report.pdf 
Dolton, P,. Howorth, C., \& Abouaziza, M. (2016). The optimal length of the working day: evidence from Hawthorne experiments. University of Sussex, mimeo.

Eurydice (2018) The organisation of school time in Europe. Primary and general secondary education - 2018/19. Eurydice facts and figures. Luxembourg: Publications Office of the European Union.

Feng, L., \& Sass, T. R. (2018). The Impact of Incentives to Recruit and Retain Teachers in "Hard-to-Staff" Subjects. Journal of Policy Analysis and Management, 37(1), 112135.

Fritz, C., \& Sonnentag, S. (2005). Recovery, health, and job performance: effects of weekend experiences. Journal of Occupational Health Psychology, 10(3), 187-199.

Fulbeck, E. (2014) Teacher mobility and financial incentives: A descriptive analysis of Denver's ProComp, Educational Evaluation and Policy Analysis, 36(1): 67- 82.

Gazioglu, S., \& Tansel, A. (2006). Job satisfaction in Britain: individual and job related factors. Applied Economics, 38(10), 1163-1171.

Gibson, S., Oliver, L. and Dennison, M. (2015). Workload challenge: Analysis of teacher consultation responses. Department for Education Research Report DfE-RR445. London: Department for Education.

Goldhaber, D., Destler, K. and Player, D. (2010) Teacher labor markets and the perils of using hedonics to estimate compensating differentials in the public sector, Economics of Education Review, 29(1):1-17.

Green, F., Felstead, A., Gallie, D., \& Henseke, G. (2018). Work Intensity in Britain - First Findings from the Skills and Employment Survey 2017. London: Centre for Learning and Life Chances in Knowledge Economies and Societies, UCL Institute of Education.

Han, K., Trinkoff, A. M., \& Gurses, A. P. (2015). Work-related factors, job satisfaction and intent to leave the current job among United States nurses. Journal of Clinical Nursing, 24(21-22), 3224-3232.

Harrington, J. M. (2001). Health effects of shift work and extended hours of work. Occupational and Environmental Medicine, 58, 68-72.

Innstrand, S. T., Langballe, E. M., Falkum, E., \& Aasland, O. G. (2011). Exploring within-and between-gender differences in burnout: 8 different occupational groups. International Archives of Occupational and Environmental Health, 84(7), 813-824.

Jacob, R., Goddard, R., Kim, M., Miller, R., \& Goddard, Y. (2015). Exploring the causal impact of the McREL Balanced Leadership Program on leadership, principal efficacy, instructional climate, educator turnover, and student achievement. Educational Evaluation and Policy Analysis, 37(3), 314-332.

Jeon S. H, Leem J. H., Park S. G., Heo Y. S., Lee B. J., Moon S. H., Jung D. Y., \& Kim H. C. (2014). Association among Working hours, occupational stress, and presenteeism among wage workers: results from the second Korean working conditions survey. Annals of Occupational and Environmental Medicine, 26(6), 1-8.

Jerrim, J., \& Sims, S. (2019). The Teaching and Learning International Survey (TALIS) 2018. London: Department for Education.

Johnson, S., Cooper, C., Cartwright, S., Donald, I., Taylor, P., \& Millet, C. (2005). The experience of work-related stress across occupations. Journal of Managerial Psychology, 20(2), 178-187.

Kodz, J., Davis, S., Lain, D., Strebler, M., Rick, J., Bates, P., ... \& Trinczek, R. (2003). Working long hours: a review of the evidence. Volume 1-Main report. Employment Relations Research Series, 16.

Kraft, M. A., Marinell, W. H., \& Shen-Wei Yee, D. (2016). School organizational contexts, teacher turnover, and student achievement: Evidence from panel data. American Educational Research Journal, 53(5), 1411-1449. 
Messenger, J. C., Lee, S., \& McCann, D. (2007). Working time around the world: Trends in working hours, laws, and policies in a global comparative perspective. Routledge.

Ofsted. (2019). Teacher well-being at work in schools and further education providers. Accessed 31/07/2019 from https://www.gov.uk/government/publications/teacher-wellbeing-at-work-in-schools-and-further-education-providers

Pencavel, J. (2014). The productivity of working hours. The Economic Journal, 125(589), 2052-2076.

Persaud, H., \& Williams, S. (2017). Long working hours and occupational stress-related illness and injury: mini review. Journal of Health Science \& Education, 1(3), 1-4.

See, B.H. and Gorard, S. (2019). Why don't we have enough teachers? A reconsideration of the available evidence. Research Papers in Education.

Sellen, P. (2016). Teacher workload and professional development in England's secondary schools: insights from TALIS. London: Education Policy Institute.

Sims, S. (2018a). Essays on the recruitment and retention of teachers [Doctoral Thesis]. UCL Institute of Education.

Sims, S. (2018b). What happens when you pay shortage subject teachers more money? Simulating the effect of early-career salary supplements on the supply of shortagesubject teachers in England. London: Gatsby Foundation.

Sutton, R. E., \& Wheatley, K. F. (2003). Teachers' emotions and teaching: A review of the literature and directions for future research. Educational Psychology Review, 15(4), 327-358.

Thomsen, I., \& Villund, O. (2011). Using register data to evaluate the effects of proxy interviews in the Norwegian Labour Force Survey. Journal of Official Statistics, 27(1), 87-98.

TNS-BMRB (2014). Teacher workload survey 2013. London: Department for Education.

Tomioka K., Morita N., Saeki K., Okamoto N., \& Kurumatani N. (2011). Working hours, occupational stress and depression among physicians. Occupational Medicine, 61(3), 163-170.

Wadsworth, E. J., Allen, P. H., Wellens, B. T., McNamara, R. L., \& Smith, A. P. (2006). Patterns of fatigue among seafarers during a tour of duty. American Journal of Industrial Medicine, 49(10), 836-844.

Waters-Weller, C. (2009) Attracting veteran teachers to low socioeconomic status schools: Initiatives and considerations, US, ProQuest Information and Learning, 69: 2979-2979

West, K. L. (2014). New measures of teachers' work hours and implications for wage comparisons. Education Finance and Policy, 9(3), 231-263.

Wunder C., Heineck G. (2013). Working time preferences, hours mismatch and well-being of couples: are there spillovers? Labour Economics, 24, 244-52.

Worth, J., Lynch, S., Hillary, J., Rennie, C. \& Andrade, J. 2018. Teacher workforce dynamics in England. Slough: NFER. Accessed 31/07/2019 from https://www.nfer.ac.uk/media/3111/teacher_workforce_dynamics_in_england_final_r eport.pdf 